\title{
Measuring deep time: the Sidereal Year and the Tropical Year in Maya inscriptions
}

\author{
Michael J. Grofe \\ Department of Anthropology, American River College, \\ 4700 College Oak Drive, Sacramento, CA 95841, USA \\ email: grofem@arc.losrios.edu
}

\begin{abstract}
Maya inscriptions contain numerous examples of long intervals of time that count both backward and forward from a fixed point of historical reference to specific mythological dates, often thousands of years in the past or future. This paper considers the evidence that these intervals incorporated precise calculations of both the sidereal year and the tropical year. Furthermore, it outlines a specific methodology for assessing the likelihood that these distance numbers were either intentionally calculated to incorporate these astronomical measurements, or if these results are merely coincidental.
\end{abstract}

Keywords. Maya inscriptions, sidereal year, tropical year

\section{Introduction}

To a casual observer, the length of a year appears to be measurable both by the return of the sun to the same position on the horizon during sunrise or sunset, and also by the reappearance of a heliacally rising star. During the lifetime of even an astute observer, these measurements appear to be equivalent. However, accurately recorded observations over many generations potentially reveal a significant difference between these two measurements as the tropical year begins to drift backwards from the sidereal year, resulting in the phenomenon of the precession of the equinoxes.

The Maya are known to have measured the tropical year with some accuracy using horizon based architectural alignments to specific days of the year ${ }^{1}$, some of which include a fixed 260-day count that may indirectly refer to the two zenith passages of the sun at $14.8^{\circ} \mathrm{N}$ latitude in southern Mesoamerica ${ }^{2}$. However, the question remains whether the Maya also recorded measurements of the sidereal year, and whether they were aware of the accumulated difference between these two measurements:

1) The Tropical Year: A year can be measured by the return of the sun to any fixed point on the horizon, whether it refers to the solstices or equinoxes, or to another chosen

1 Alignments to solstice and equinox positions are relatively rare to absent in Maya architecture. While Late Preclassic 'E-Group' monuments are common, few of them actually align to the solstices, while many align to the quarter-days at the midpoint between the solstices (March 23 and September 21), rather than to the true equinoxes (Aveni \& Hartung 1989; Aveni, Dowd \& Vining 2003; Šprajc 2001).

2 The importance of the solar zenith passage in Mesoamerica and its relationship to the 260-day calendar and the calculation of the tropical year were first noted by Nuttall (1928), Apenes (1936) and Girard (1948). Merrill (1945) and Malmström (1973; 1978; 1997) independently proposed that the zenith passage at $14.8^{\circ} \mathrm{N}$ latitude corresponds to the Era Base in the Long Count. Measurements of the zenith passage in Mesoamerica are discussed by Tichy (1981), Aveni \& Hartung (1981), Coggins (1982) and Broda (2000; 2006). So-called 'zenith-sighting tubes' have been identified outside the Maya area in Teotihuacan, Monte Alban and Xochicalco, though these often allow in light for multiple days in addition to the zenith, some fixing a period of 260 days. 
day. In the Mesoamerican tropics, the unique phenomena of solar zeniths and nadirs ${ }^{3}$ may have enabled a high degree of accuracy. Depending on what time of year the measurements are taken, the value for the length of the year differs slightly (due to the complications of precessional wobbling interacting with the changing speed of the earth in its elliptical orbit), and this is further complicated by the fact that the length of the tropical year changes slightly over time due to the changing rate of precessional wobbling itself. We currently take a yearly average of the four different measurements of the length of the tropical year from the two solstices and the two equinoxes as the mean tropical year of 365.24219 days (Meeus \& Savoie 1992: 42).

2) The Sidereal Year: A year can also be measured using the first appearance of stars or asterisms like the Pleiades after close conjunction with the sun. All that is needed for a basic measurement of the sidereal year are consistent observations of heliacal star risings recorded over several generations, particularly using stars close to the ecliptic. Over the course of an average lifetime, it appears as though a star becomes first visible on the same day of the tropical year, but this is not the case over hundreds of years, since the sidereal year - or the time for the sun to apparently return to the same star - is slightly longer than the tropical year. Unlike the tropical year, the sidereal year of 365.25636 days is highly stable over many thousands of years as it reflects the regular period of the earth's orbit around the sun relative to the stars. ${ }^{4}$ In fact, early astronomers in Egypt and Mesopotamia used heliacal star risings as a primary measurement of the length of the year (North 2008: 28-30, 51). Ancient Egyptians used the heliacal rising of the Decan stars to organize their year into ten-day periods, and the heliacal rise of Sirius announced the annual flood of the Nile. Perhaps more relevant to this discussion, Babylonian astronomers used only the sidereal year as the length of their 'year' (Neugebauer 1969: 140).

Hipparchus is widely recognized as having first attempted to calculate the accumulating difference between the sidereal and tropical years that manifests as the precession of the equinoxes, which he himself discovered and named in the Second Century BC (Toomer 1978; Evans 1998: 259-261). He estimated that the difference did not amount to more than one day per century, while the current calculation places it at around one day every 71 years or so. But it is important to realize that one need not understand the dynamics of precession to record the regular pace of the sidereal year over centuries of time. Careful, naked-eye observations of heliacal star risings and long-term record keeping are sufficient alone, though Hipparchus also utilized the sidereal position of total lunar eclipses coordinated with the tropical year. He thus used a slightly inaccurate tropical year together with an estimation of the apparent degrees of precession rather than directly measuring intervals of the sidereal year itself.

\section{The Long Count Era base as a Tropical Year measurement in deep time}

By far the most common reference to deep time in Maya inscriptions is the Era base of the Long Count, which utilizes a vigesimal positional system of repeating cycles of 360 days. As an exact count of days from a remote Era base, the Long Count closely resembles the Julian Day Number system established by Joseph Scaliger in 1583, which continues

3 The nadir, or the anti-zenith, is indirectly measurable via architectural alignments to the point on the horizon directly opposite to the sun's position on the horizon on the day of the solar zenith. Milbrath (1988) first suggested that the Maya were interested in the solar nadir, and similar orientations to the sun on the local nadir have been noted in the Palenque Temple of the Sun (Mendez et al. 2005).

4 The long-term stability of the sidereal year is derived from expressions for IAU 2000 precession quantities (Capitaine et al. 2003). 
to be useful for the exacting needs of astronomers (Moyer 1981). Given this similarity, perhaps it should come as no surprise that the Long Count could also have been utilized to record and calculate precise astronomical measurements and project them into the remote past and future.

Following the two widely accepted GMT correlations of the Long Count with the Gregorian proleptic calendar, the Era Base of the Long Count occurs on 4 Ajaw 8 Kumk'u, an irregular day in the Calendar Round that corresponds to either August 11 or 13, 3114 BC. In either case, August 13 corresponds to one of the two solar zenith passages at the latitude of $14.8^{\circ} \mathrm{N}$, the location in southern Mesoamerica where the two zenith passages are 260 days apart, and where the system may have originated. Such a precise correspondence implies not only an intentional and highly accurate calculation of the tropical year, it also suggests the means by which such a calculation could have been performed using the solar zenith. ${ }^{5}$ If the originators of the Long Count did in fact make such a calculation, which is a big 'if' for some, it would follow that at the time of the earliest attested Long Count date from Chiapa de Corzo in $36 \mathrm{BC}^{6}$, Mesoamericans had already achieved a measurement of the tropical year that was unsurpassed until Johannes Kepler in $1627 .^{7}$ The significance of such a potential early achievement is certainly noteworthy as a 'first', though the evidence for such accuracy is difficult to assess.

Thompson (1927: 12) proposed that the originators of the Long Count utilized the equation of 1507 tropical years with $1508 \times 365$ days, giving a tropical year value equivalent to the current measurement of 365.2422 days. However, he later retracted his proposal, stating that he was "crediting the Maya with too great accuracy for such an early period in their history" (Thompson 1932: 370-371). Nevertheless, in the same publication he cited a later deep time example from the Palenque Tablet of the Foliated Cross that demonstrates a possible use of half this cycle as $754 \times 365$ days (ibid.: 402).

After analyzing dates on Copán Stela A using his 'determinant theory', ${ }^{8}$ Teeple (1930: 70-74) concluded that the Copán astronomers had calculated a tropical year of 365.2419355 days, slightly more accurate than the Gregorian year of 365.2425 days. Interestingly, Teeple's Copán tropical year provides an easily measurable whole multiple of 22,645 days $=62$ years, which requires skipping a leap-year every 124 years. Within several deep time intervals from the Serpent Series in the Dresden Codex, I found Teeple's

${ }^{5}$ Both Merrill (1945) and Malmström (1973) first independently noted the relationship between the Long Count Era base and the August 13 zenith at $14.8^{\circ} \mathrm{N}$ latitude. Thompson (1950: 152) became a staunch critic of this astronomical hypothesis, while Aveni (2009: 72-73, 82-83) notes that it is difficult to accurately measure the zenith to within two days because the sun is an extended object and light source. However, both Rice (2007: 48) and Aveni (2009: 83) conclude that the Era base likely commemorates the seasonal agricultural harvest when people would gather at the time of the August 10-13 solar zenith, within a generalized band of latitude in southern Mesoamerica where the Long Count originated. Thus, they avoid conclusions about the accuracy implied by any specific date or latitude.

6 The Chiapa de Corzo Long Count date has been reconstructed as 7.16.3.2.13, corresponding to December 6-8, 36 BC using the GMT correlation constants. The next earliest Long Count date appears on Tres Zapotes Stela C as 7.16.6.16.18 (Coe 1994: 76).

${ }^{7}$ For a discussion of the history of the measurement of the tropical year in the West, see Meeus \& Savoie (1992: 41).

8 Determinant dates reconciled the drift of the 365-day cycle through the tropical year. Teeple (1930), and later Thompson (1932), explored the inscriptions and derived various examples. However, this determinant methodology preceded a more complete understanding of the script, and when it was later realized that most of the dates cited are actually historical, rather than exclusively astronomical, the foundations of determinant theory were criticized (Aveni 2001: 165). Nevertheless, it remains quite likely that many historical dates were timed to coincide with significant positions in the tropical year, and determinant theory deserves further exploration. 
value for the Copán tropical year to be highly productive, particularly with the placement of the base date $9 \mathrm{~K}^{\prime}$ an $12 \mathrm{~K}^{\prime}$ ayab on a precise summer solstice over 30,000 years prior to the Long Count Era base in 3114 BC (Grofe 2007: 74-85). The productivity of such constant values in different places and times suggests some historical continuity, and it provides us with the possibility of testing.

Both Teeple and Thompson concluded that different cities developed their own calculations of the tropical year, with some values surpassing the Gregorian measurement by the Late Classic. Particularly in Quirigua, Thompson (1932: 389) believed that this site had gradually developed a high level of accuracy. Interestingly, Quirigua contains some of the longest deep time calculations into the past, including an interval found on Stela F that Thompson (1950: 315) calculates as 91,683,930 × 360 days. Barbara MacLeod (pers. comm., 2008) has recently determined that this interval is exactly equivalent to $90,368,021$ tropical years of 365.2422 days. But we bear the burden of having to test such a result to draw any conclusions.

If the Maya were capable of calculating the tropical year with great accuracy, we would expect to find evidence for this and other astronomical measurements within some of the other deep time intervals found throughout the inscriptions. Several of these intervals reach back to target specific dates millions of years earlier than the Long Count Era base itself. Other intervals span shorter periods of hundreds or thousands of years. All of these deep time intervals require further analysis using an adequate methodological approach. While we may be able to test large intervals for suspected astronomical constants that can be compared with other texts, shorter intervals are more likely to provide reliable results, since there is less chance for vast, accumulated errors based on slight differences in the values chosen.

\section{The completion of the thirteenth Bak'tun}

Edmonson (1988: 120) first suggested that the Long Count was devised to intentionally place the completion of the Great Cycle of 13 Bak'tuns on the winter solstice, which falls on December 21, 2012 AD. Using the 584283 Julian Day GMT correlation with the Era base, Edmonson concluded that the placement of the Era base was a mere consequence of this predictive, future date. Yet, the evidence would seem to weigh more heavily in favor of an intentional back-calculation of the August 13 zenith on the Era base, using the alternate 584285 GMT correlation, though one must consider the possibility of a two-day error in either calculation. The majority of mythological texts describe events on the Era base as a completion of a previous Great Cycle of 13 Bak'tuns, while only one surviving text from Tortuguero Monument 6 mentions the future completion of this cycle. Chronologically, there is simply no evidence that the originators of the Long Count were even interested in any cycle of 13 Bak'tuns, since the very first historical reference to the Era base as a completion of 13 Bak'tuns appeared on the now destroyed Stela 23 in Copán, with the Late Classic date of 9.10.18.12.8, in 650 AD. It appears that this novel idea diffused from Copán, and the commemoration of Tortuguero Monument 6 follows shortly after this.

Given the evidence, it is far likelier that the originators of the Long Count first backcalculated the tropical year position of the Era base to target the August 13 solar zenith ${ }^{9}$,

${ }^{9}$ Elsewhere (Grofe 2007: 91-92) I discuss the possible sidereal reasons for the choice of the Long Count Era base year as 3114 BC, when the Pleiades would have heliacally risen on the day of the vernal equinox, due east on the celestial equator. This parallels their later heliacal rise on the April 30 zenith at $14.8^{\circ} \mathrm{N}$ latitude, where they precisely cross the zenith in the 2 nd century $\mathrm{BC}$, at the time and place where the Long Count is thought to have originated. A count of one $\mathrm{k}^{\prime}$ atun begun on the August 13 zenith ends precisely on the April 30 zenith. 


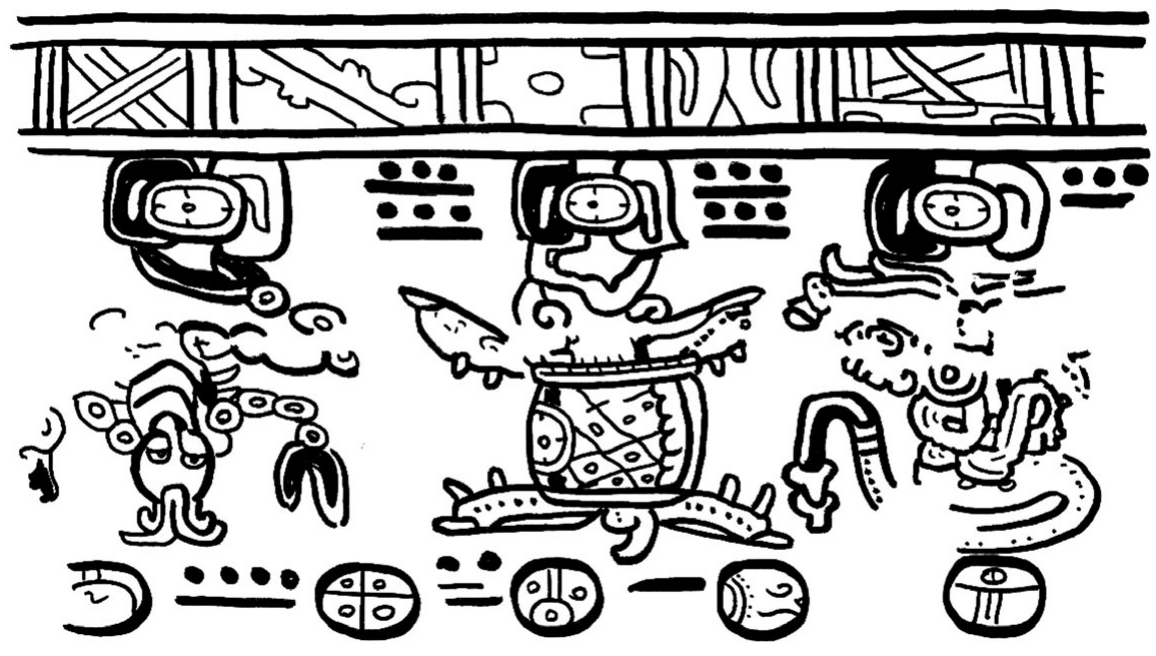

Figure 1. The Paris Codex 'Zodiac'. Scorpion at left; Turtle in the center; Rattlesnake at right. Each devours (or stings) the glyph for a solar eclipse beneath a Sky Band, representing the ecliptic. Drawing by author after FAMSI photograph.

while the next 13 Bak'tun completion follows as a consequence of this choice-perhaps simply as the next 4 Ajaw date to close a Bak'tun. However, if Mesoamerican astronomers were capable of back-calculating the position of the tropical year with great accuracy, they would conceivably have been able to notice that the future completion of 13 Bak'tuns will occur either on or very close to a winter solstice. ${ }^{10}$ It is possible that such a fortuitous coincidence led to a localized interest both in this future date, and in the idea of a Great Cycle of 13 Bak'tuns itself.

While the question of the significance of the tropical year within the Long Count has received wider acceptance, Jenkins' (1998) popularized proposal that the Great Cycle completion in 2012 intentionally predicts the sidereal position of the winter solstice sun in conjunction with the Milky Way has received much more criticism (see Aveni 2009; Van Stone 2010). Whereas the sensationalized interpretations of what is expected to occur on this date warrant their own socio-cultural analyses, the question of whether Mesoamericans were capable of calculating the sidereal year and precession remains a legitimate one, as do questions regarding how these phenomena may have been variously interpreted.

The text on Tortuguero Monument 6 text is bracketed by the birth date of the ruler Bahlam Ajaw on the missing left flange, and by the future date of the 13-Bak'tun completion on the right flange. Elsewhere (Grofe 2010) I have noted that these two dates place the sun within at least three days of the same sidereal position, regardless of what correlation is used. Such a sidereal parallel suggests an astronomical motivation for the localized association between the birth of a ruler and this future date in deep time. But is this sidereal parallel a mere post-hoc coincidence, enhanced by our easy access to visual astronomy programs? How might we determine if such a parallel was intentional? As we shall see, there are additional examples of these types of date pairs and distance numbers that incorporate whole multiples of the sidereal year in deep time calculations.

10 In his recent critique of the 2012 meme, Aveni (2009: 81) concedes that "It is conceivable, then, that the two creation events are keyed to important positions of the sun cycle." However, he maintains that the accuracy of such calculations is difficult to determine. 


\section{The Serpent Series and the Sidereal Year}

Evidence from the Paris Codex suggests that the Maya took an interest in the sidereal positions of constellations along the ecliptic (Fig. 1). Severin (1981) originally suggested that the Paris 'zodiac' represents the precessional movement of the vernal equinox through consecutive zodiacal constellations. However, Bricker \& Bricker (1992) have since confirmed that the ordering of the constellations is not consecutive, and that they reflect the sidereal positions of successive solar eclipses, symbolically devoured by each constellation. Recent research demonstrates that the Maya were particularly interested in the sidereal positions of various planets (Aveni, Bricker \& Bricker 2003).

The preface from the Serpent Series on pages 61 and 69 in the Dresden Codex (Fig. 2) contains what I read as a large and unusual distance number of 5,482,135 days (Grofe 2007: 66, 86-94). This interval is only two days greater than a whole multiple of 15,009 sidereal years, and it suggests the Maya may have had a sidereal year that we can express as 365.256512759 days. While this distance number places the sun in the same sidereal position, it provides a remainder of 218 days when using Teeple's Copán tropical year,

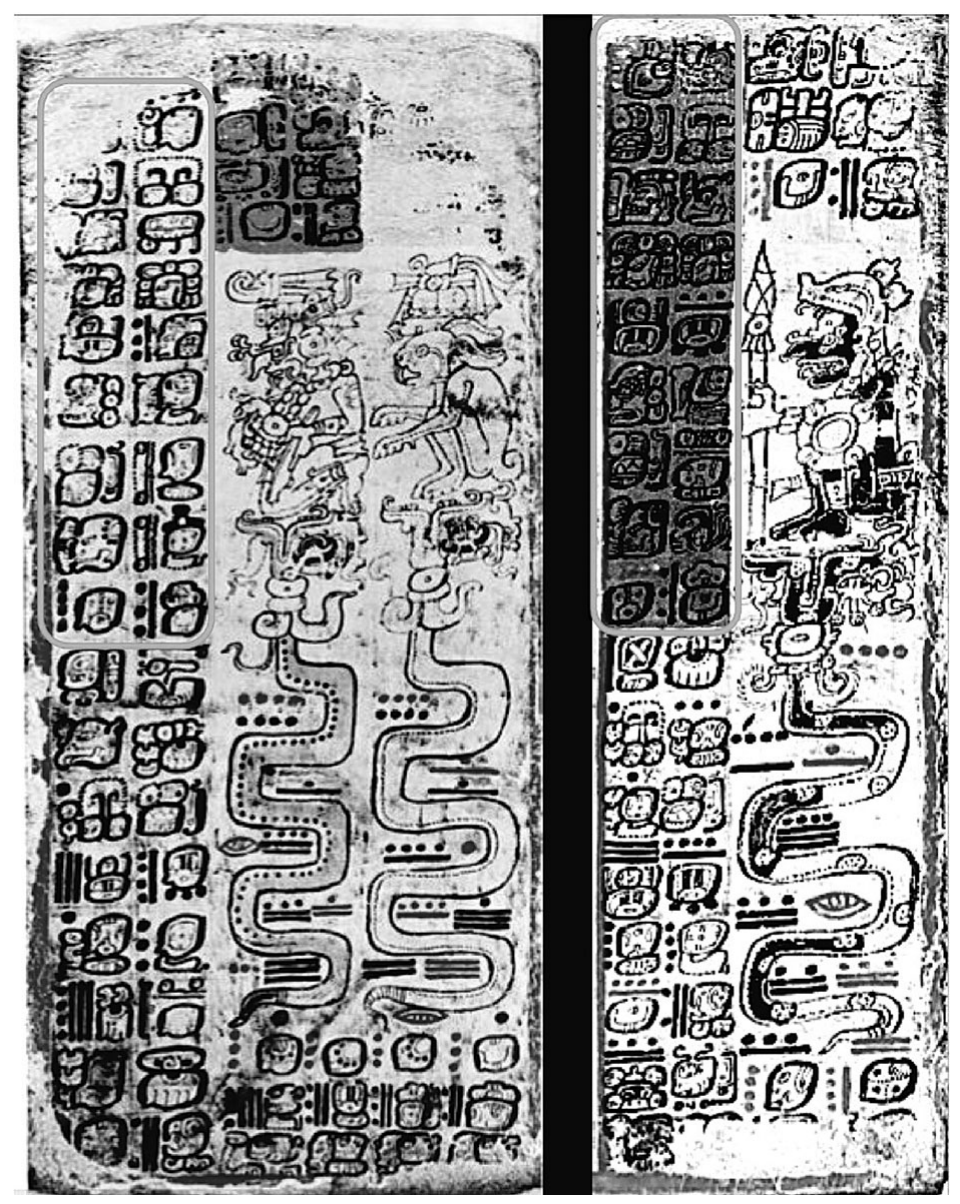

Figure 2. The Serpent Series Introductory Distance Number. Page 61 (left) and page 69 (right). Matching interval in upper left of each image (cartouches added). Three of the five serpents are visible containing six of the ten Serpent Numbers, which are also shown. Each Serpent Number is a distance number counting forward from the Serpent Base $9 \mathrm{~K}^{\prime}$ an $12 \mathrm{~K}^{\prime}$ ayab, over 30,000 years prior to the Era base in 3114 BC. Image compiled by author from FAMSI photograph. 


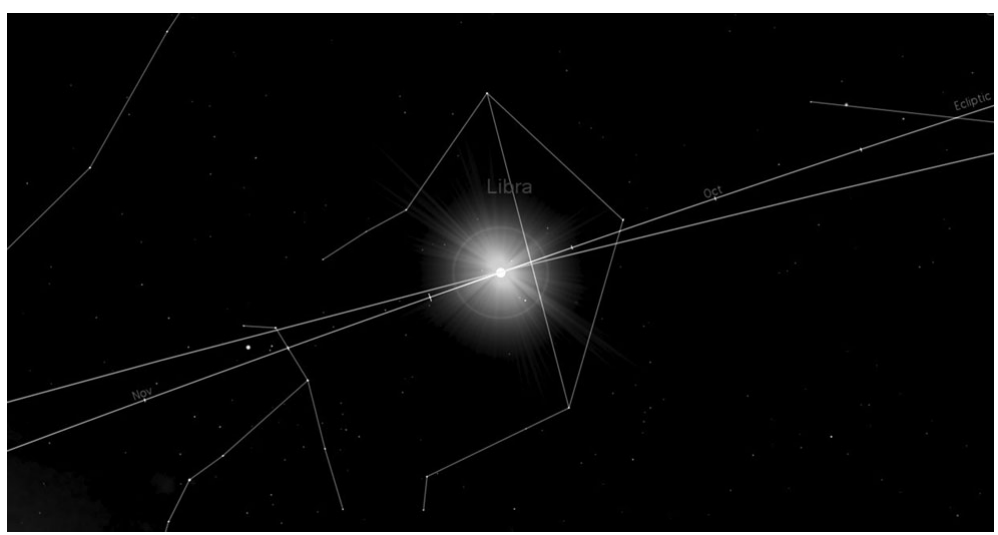

Figure 3. Sidereal position of the sun on Serpent Number 3a. 10.04.06.15.14, 3 Ix 7 Pax, October 30, $915 \mathrm{AD}$ (10/25 Julian). Sun at ascending lunar node near solar nadir $14.8^{\circ} \mathrm{N}$. Identical sidereal position as on Serpent Base. Image by author courtesy of Starry Night Pro 6.2.3: Imaginova.

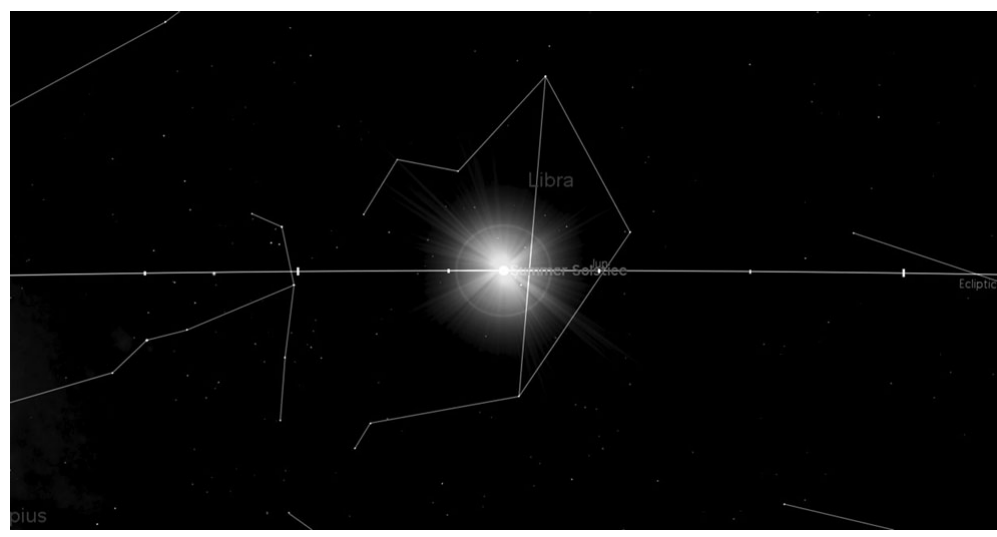

Figure 4. Theoretical reconstruction of sidereal solar position. Serpent Base, $9 \mathrm{~K}$ 'an 12 K'ayab, June 22, 33,146 BC. Image by author courtesy of Starry Night Pro 6.2.3: Imaginova.

and this 218-day interval is referenced throughout the seasonal table accompanying the Serpent Series. ${ }^{11}$ The Maya did not use decimals, and it is likely that they arrived at such a value by adding a whole number of days to either an interval of tropical years, 365 days, or 364-day computational years. One possibility would be the equivalence of 343 sidereal years $=343$ Copán tropical years +5 days.

Beyer (1943) first noticed that the Serpent Numbers count forward from a base date some 30,000 years prior to the Long Count Era base, which is just over twice the distance number from the preface. I subsequently found that the vast $12,438,810$-day distance number between the Serpent Base and Serpent Number 3a on page 62 of the Dresden Codex is also within a day of a whole multiple of the same sidereal year value found

11 Bricker \& Bricker (1988) propose that the seasonal table following the Serpent Series was used to commensurate the tropical year with the 365-day cycle and the eclipse cycle. Their reading of the Introductory Distance Number differs from mine, while their interpretation of this interval has little bearing on their productive conclusions about the function of the seasonal table. They do not address the purpose of other immense distance numbers in the Serpent Series. For a further critique of their interpretation, see Grofe (2007: 59). 


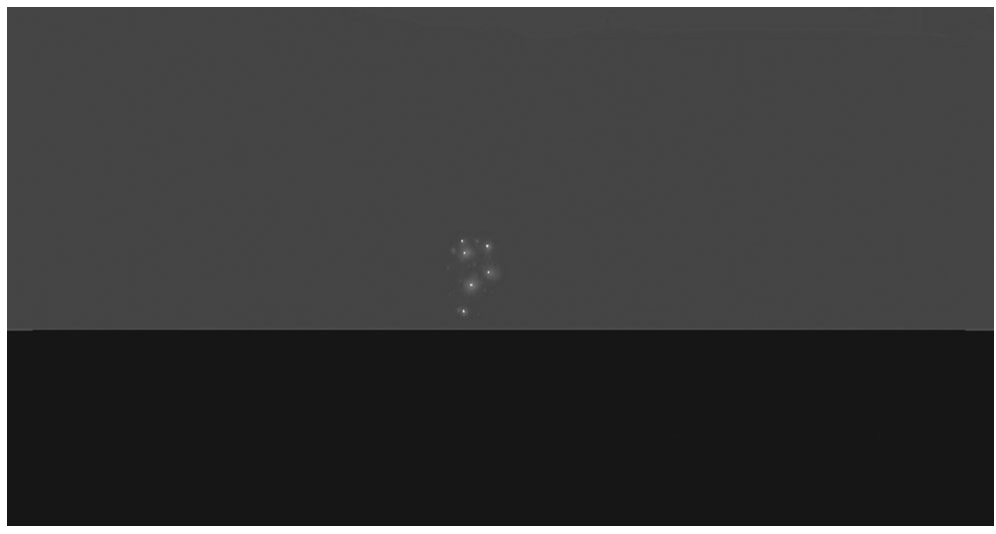

Figure 5. The Pleiades last visible rising at the horizon at sunset, when the sun is in the sidereal position of the Serpent 3a and the Serpent Base. Image by author courtesy of Starry Night Pro 6.2.3: Imaginova.

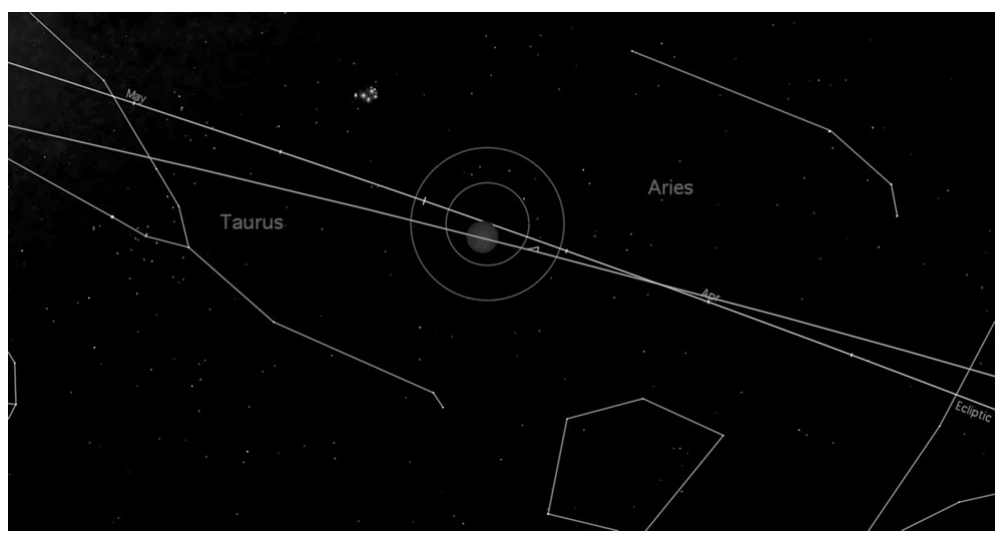

Figure 6. Total Lunar eclipse on date of Serpent 3a: 10.04.06.15.14, 3 Ix 7 Pax, October 30, 915 $\mathrm{AD}$ (10/25 Julian). Showing lunar node, with penumbra as large circle, and umbra as smaller circle around the moon. Note the Pleiades to the upper left of the moon. Image by author courtesy of Starry Night Pro 6.2.3: Imaginova.

within the initial distance number from the preface. ${ }^{12}$ If used as a sidereal year value, repeating multiples of 365.256512759 days place the sun in the same position in Libra on Serpent 3a (Fig. 3), October 30, 915 AD, as it theoretically would have appeared on the Serpent Base on the summer solstice in 33,142 BC using the Copán tropical year (Fig. 4). This sidereal position curiously places the sun opposite the Pleiades on a day when they would have been last visible touching the horizon and rising at sunset (Fig. 5 ). This configuration suggests the very type of astronomical observation needed to make

12 In his critique of my work, Aveni (2009: 105) clearly misunderstands that I am attempting to derive an indigenous Maya value for the sidereal year, which remains stable for thousands of years, rather than using any contemporary value for precession, which relies on the length of the tropical year and therefore does vary over time. Aveni's calculations of the change in the rate of precession are in error throughout, in that he miscalculates that the decreased rate of precession in the past leads to a shorter cycle of precession when it actually leads to a longer cycle (ibid.: 96). In addition, Aveni incorrectly interprets my results by claiming that the 218-day shift of the Copán tropical year occurs over the $30,000+$ year interval between the Serpent Base and the Era Base, rather than over the correct 15,009 sidereal year interval from the introductory distance number in the preface. 
such a calculation of the sidereal year. For much of Maya history, the disappearance and reappearance of the Pleiades following its conjunction with the sun has coincided with the planting season, and Maya farmers continue to keep track of its motion (Milbrath 1999: 258). As a recognizable marker close to the ecliptic, the Pleiades serve as a logical choice for sidereal calculations.

The terminal date for Serpent Number 3a also occurs on the date of a total lunar eclipse on 10.04.06.15.14, 3 Ix 7 Pax, October 30, 915 AD (10/25 Julian) (Fig. 6). Of the ten Serpent Numbers, this is the only one to fall on the day $3 \mathrm{Ix}$ - one of the five possible entry days associated with the seasonal table. However, I found that for all of the Serpent Numbers, the closest day 3 Ix places the sun precisely at a lunar node, though not directly on a visible eclipse, and this suggests that the Maya were actively tracking the regression of the lunar nodes - yet another technique for calculating the sidereal year. In fact, we find that the interval between the Serpent Base and Serpent Number 3a is a whole multiple of the eclipse year of 346.62 days, used throughout the Serpent Series. Therefore, the Serpent Base date would have also theoretically placed the sun at the same lunar node, likely with the intention of calculating a lunar eclipse next to the Pleiades as an ancient precursor to the identical eclipse on October 30, 915 AD.

The remaining texts above each Serpent Number pair contain a known reference to eclipses as $c h i b$ ', 'bite'. The serpents themselves for which these long distance numbers are named are also depicted with their mouths open beneath various deities (Fig. 2). Two similar serpents are depicted biting images of eclipses in the Dresden Lunar Table on pages 56 and 57 (Fig. 7a), and we find this same imagery among the various animals in the Paris zodiac as they each devour the sun (Fig. 1). One of these animals is recognizable as a rattlesnake, and this has been identified as a constellation associated with the Pleiades, which the Yucatec Maya refer to as $t z$ ' $a b^{\prime}$, the 'rattle' of a rattlesnake. ${ }^{13}$ In her discussion of the possible function of the Serpent Series, Milbrath (1999: 258-259) proposed that the use of serpent imagery is suggestive of the Pleiades, while the long periods involved in the tables evoke the precession of the equinoxes. The evidence from the above calculations of the sidereal year supports both of these proposals.

Within the Serpent Series, both Barbara MacLeod and I have since identified another back-calculated solar eclipse linked to two additional pairs of dates with distance numbers that utilize whole multiples of precisely the same sidereal year value found in the introductory distance number and the interval between the Serpent Base and Serpent Number 3a. But is there evidence for an earlier precedent for this value?

\section{Tikal Stela 10}

Tikal Stela 10 (Fig. 7b) contains one of the earliest and longest deep time intervals, with a challenging text and an abbreviated Initial Series Introductory glyph followed only by the day 8 Manik, with what appears to be YAx-K'ATUN-na-hi?-ya, 'first/new $\mathrm{k}^{\prime}$ atun [in the past]', and a YAx-CH'AB 'first sacrifice' event in the life of the departed ruler $\mathrm{K}^{\prime}$ an Chitam. I have tentatively reconstructed this date as 9.00.00.12.07, 8 Manik $15 \mathrm{Xul}$, on August 12, $436 \mathrm{AD}$ (8/11 Julian). ${ }^{14}$ This date is immediately followed by a

13 For a review of the various interpretations of the Paris zodiac, see Milbrath (1999: 254-257).

14 A 'first sacrifice' event usually takes place when the king is young. In this case, the date given corresponds to a 'first/new k'atun', which may reference the important k'atun following 9.0.0.0.0, when $\mathrm{K}^{\prime}$ an Chitam was much younger. The first 8 Manik after this falls on 9.0.0.12.7, 8 Manik 15 Xul, August 12, 436 AD (8/11 Julian), essentially on the Copán zenith. This interpretation parallels the later referenced date on 9.2.11.7.8, 4 Lamat 6 Yaxk'in on August 13, 486 (8/12 Julian) as an intentional tropical year measurement. 

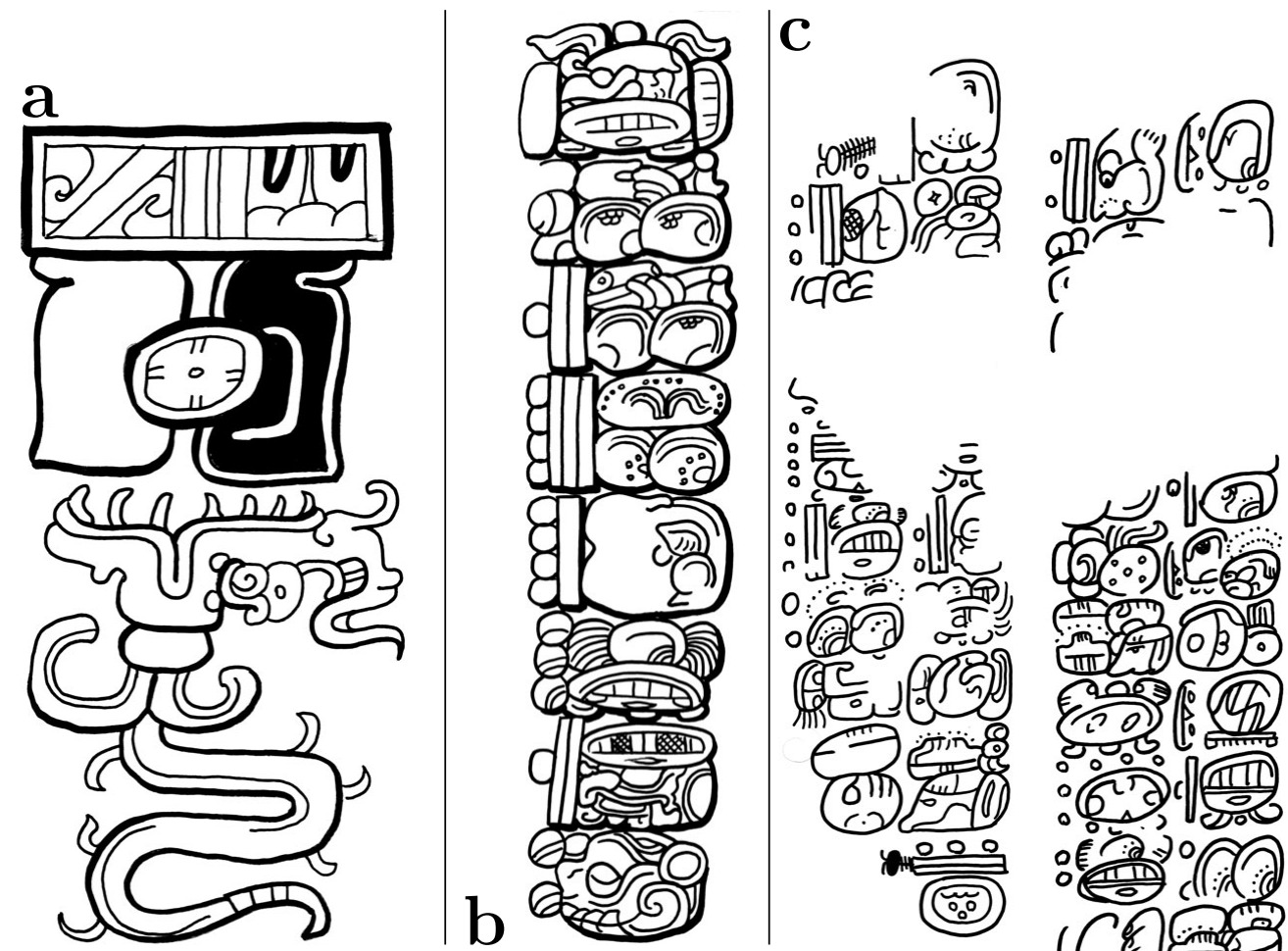

Figure 7. (a): Eclipse Serpent from Dresden Lunar Table, page 57. Drawing by author from FAMSI photograph. (b): Distance Number 1.11.19.9.3.11.2.[0] from Tikal Stela 10. Drawing by author after W. Coe (Jones \& Satterthwaite 1982). (c): Detail of Deep Time Intervals on Naranjo Altar 1. Left: B2-B11: distance number of 2.13.13.??.17.4 from A5-A7. CHAN-chi-pu-yu-AJAW at A10-B10. Right: C1-D11: smaller distance number of 2.2.6.3.3 from C9-D10. CHAN-chi-pu-yu-AJAW at A7 and B11. Drawing by author after Ian Graham and Linda Schele (Grube \& Schele 1993).

second Initial Series, with an interval of time containing several positions above the Bak'tun, including piktuns $(8,000 \times 360$ days $)$, kalabtuns $(160,000 \times 360$ days $)$, and $\mathrm{k}^{\prime}$ inchiltuns $(3,200,000 \times 360$ days $)$. Thompson (1950: 314$)$ concludes that this is to be read as a distance number that counts forward from a much earlier base date, similar to the Serpent Series base date. As written, the distance number on Tikal Stela 10 reads 1.11.19.9.3.11.2.[0], with the $\mathrm{k}^{\prime}$ in or day position not present. This adds up to $1,841,641,600$ days, which is very close (exact to within a day) to a whole multiple of the sidereal year of 365.256512759 days identified in the Serpent Series:

\section{$1,841,641,600$ days $=5,042,050 \times(365.256512759$ days $)-0.157$ day}

This evidence suggests that the calculation of the sidereal year found within the Dresden Serpent Series derives from an ancestral measurement in the Early Classic. It is unclear whether the terminus for this enormous distance number is the unanchored date 8 Manik, or the more secure dates that follow on the west side, with 9.2.11.7.8, 4 Lamat 6 Yaxk'in, which falls on August 13, 486 (8/12 Julian), the exact date of the Era base and the celebrated Copán solar zenith. In either case, both dates are apparently linked to this zenith, while they are separated by fifty years. The text reaches its final date on 9.2.11.10.16, 7 Kib 14 Yax, October 20, 486 (10/19 Julian), on which the successor Chak 


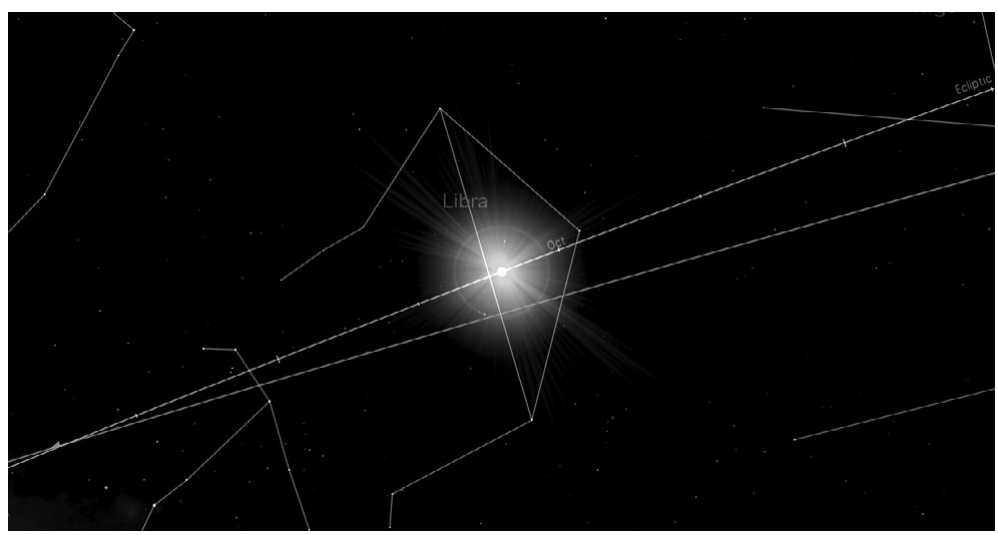

Figure 8. Tikal Stela 10 final date: 9.2.11.10.16, 7 Kib 14 Yax, October 20, 486 (10/19 Julian). Sun is one day prior to the same sidereal position of the Serpent Base in the Dresden Codex. Image by author courtesy of Starry Night Pro 6.2.3: Imaginova.

Tok Ich'aak performs another 'first sacrifice'15, which parallels that of his predecessor. But here, the sun appears just one day prior to the same sidereal position where we find the Serpent Base in Libra (Fig. 8). This suggests that the Tikal astronomers may have compared tropical year measurements with sidereal observations. Not only does the final date place the sun in essentially the same sidereal position opposite the Pleiades that we find in the Serpent Series; we also find that this long deep time distance number utilizes precisely the same value for the sidereal year identified in the Serpent Series.

\section{Naranjo Altar 1}

Naranjo Altar 1 (Fig. 7c) is an excellent example of a largely secure, shorter deep time interval that clearly links to the historical ruler Ah Wosal, while it also contains a much larger, and less secure distance number that links to the far distant past. The text mentions several mythological figures, including the 'Square-nosed-Beastie', the subject of other deep time intervals in Palenque and Copán, as well as an unusual deity named CHAN-chi-pu-yu-AJAW, with differing spelling orders (Grube \& Schele 1993). Naranjo Altar 1 references a building dedication date on 7 Kaban 5 Kayab (coordinates D12-E1), which corresponds to 9.4.10.8.17, on February 19, 525 AD (2/17 Julian) using the 584285 GMT (Fig. 9a). This date is secure, given that it counts forward by a distance number to another date just prior to the mentioning of the $\mathrm{K}^{\prime}$ atun completion on 9.6.0.0.0, 9 Ajaw 3 Wayeb (I5-H6). Immediately preceding the date 9.4.10.8.17, 7 Kaban 5 Kayab, we see an $834+$ year distance number that reads 2.2.6.3.3 (C9-D10). If we subtract this interval from the above date, we reach a date $13 \mathrm{Ix} 12 \mathrm{Xul}$, which is stated in the text (B11-C1). On this date, CHAN-chi-pu-yu was conjured (Fig. 9b):

$$
\begin{array}{ll}
\text { 9.04.10.08.17 } 7 \text { Kaban 5 Kayab } & \text { February 19, } 525 \text { AD (2/17 Julian) } \\
\hline-2.02 .06 .03 .03 & \text { February 8, } 310 \text { BC (2/13 Julian) }
\end{array}
$$

This distance number amounts to 304,623 days, and it is remarkable for several reasons:

1) The Sidereal Year: The interval of 304,623 days is very close to a whole multiple of the modern astronomical sidereal year (just 0.8 day longer), placing the sun on 7.2.4.5.14, February 8, 310 BC (Fig. 9b) in precisely the same position at which it appeared on the later date 9.4.10.8.17, 7 Kaban 5 Kayab (Fig. 9a). However, the time of year has shifted by 11 days. This appears to be yet another clear use of the calculation of the sidereal year in

\footnotetext{
15 Martin \& Grube (2000: 37, 39) anchor the final date of this sacrifice to 486 AD.
} 

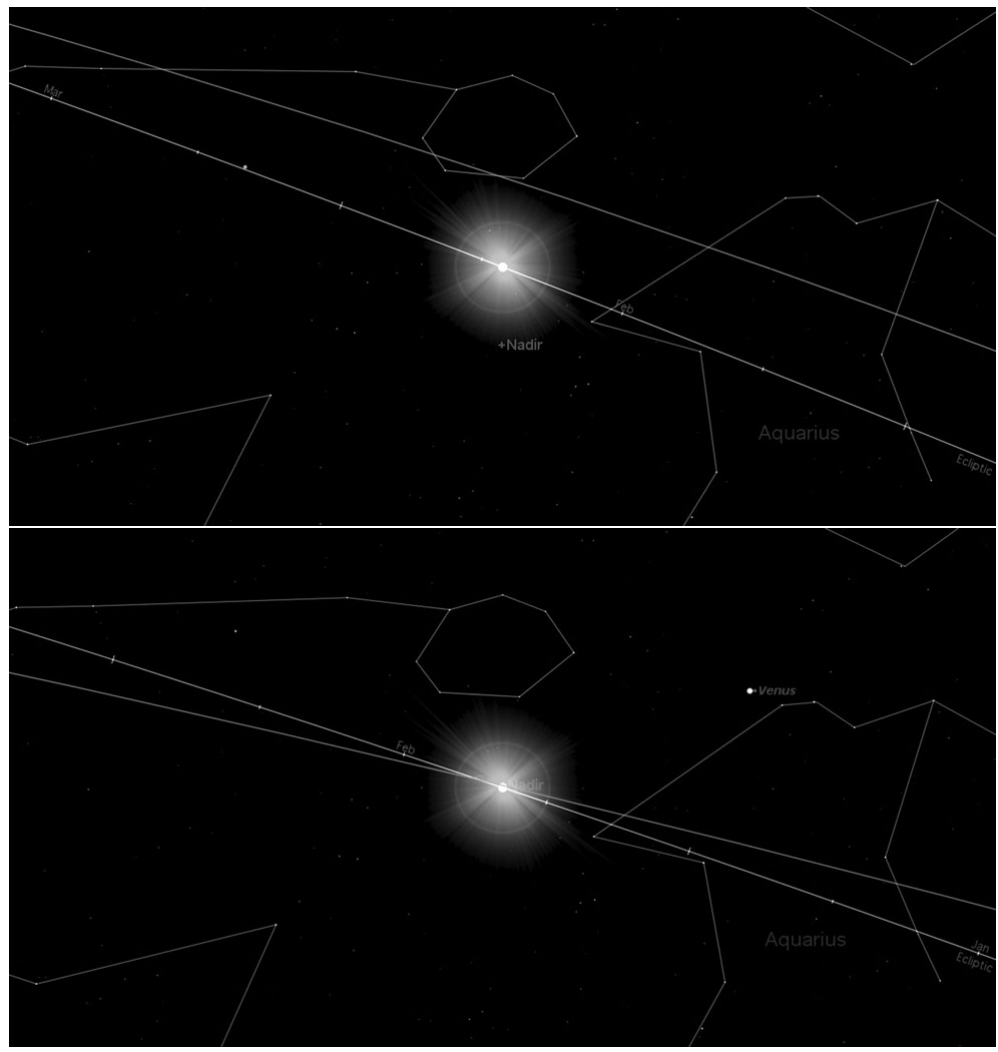

Figure 9. Naranjo Altar 1:

Top: 9.4.10.8.1, 7 Kaban 5 Kayab, February 19, 525 AD (2/17 Julian).

Bottom: 7.2.4.5.14, 13 Ix 12 Xul, February 8, 310 BC (2/13 Julian).

The sun is in the same sidereal position as on 9.04.10.8.1, above.

The sun is at the exact solar nadir at $14.8^{\circ} \mathrm{N}$. Venus is heliacally rising. The sun is exactly at a lunar node.

Images by author courtesy of Starry Night Pro 6.2.3: Imaginova.

deep time intervals. If this interval was intended as a whole multiple of the sidereal year, it is possible that the Naranjo astronomers utilized a slightly different value for the sidereal year than we see in the above examples from Tikal and the Dresden Codex. Nevertheless, it appears that they were targeting this specific day for additional astronomical reasons while still conforming to the correct day of the sidereal year position, and it did not need to be an exact whole multiple.

2) The Tropical Year and the Copán solar nadir: 304,623 days is nearly a whole multiple of our current measurement of the tropical year $(834 \times 365.2422$ days $)$, with a remainder of exactly 11 whole days. Using the 584285 GMT correlation, we reach the date February 8, 310 BC, which is a solar nadir at the latitude of Copán. February 8 is also recognizable in the ethnographic record as the beginning of the Ch'orti agricultural New Year - the ritual importance of which has been documented by Girard (1966: 832; see also Looper 2003: 127-28). At this time of year, rituals are performed to conjure the Chicchan serpents from a sacred pool that represents the central portal to the underworld, and this suggests that the name of the deity mentioned on Altar 1 may read chi-CHAN, given that it is conjured on the February solar nadir, and the central image of the altar is furthermore a known symbolic portal. 
Table 1. The Copán February solar nadir.

\begin{tabular}{lrl}
\hline Event & Long Count & Gregorian ('85 GMT) \\
\hline a) Arrival of Yax K'uk' Mo' at Ox Witik in Copan & 8.19 .11 .00 .13 & February 9, 427 AD \\
Accession of Ruler 12 in Copán & 9.09 .14 .17 .05 & February 8, 628 AD \\
Accession of Bahlam Ajaw in Tortuguero & 9.10 .11 .03 .10 & February 9, 644 AD \\
Anniversary of Ruler 12's accession & 9.10 .19 .05 .10 & February 7-8, 652 AD \\
Accession of Itzamnaah K' awiil, Naranjo & 9.17 .16 .03 .08 & February 8, 787 AD \\
Accession of Ukit Took' in Copan & 9.19 .11 .14 .05 & February 10, 822 AD \\
b) Tikal Temple IV, Lintel 2, Haab New Year 1 Pop & 9.15 .12 .11 .13 & February 8, 744 AD \\
7 Ben & & \\
c) Base date of the Dresden Venus Table & 9.09 .09 .16 .00 & February 9, 623 AD \\
Copán Temple 11, Venus station, Lunar Eclipse & 9.17 .00 .00 .16 & February 9, 771 AD \\
La Corona Gl.P.4, Venus Heliacal Rise, Lunar & 9.12 .14 .14 .14 & February 7, 687 AD \\
Eclipse & & \\
d) Naranjo Altar 1, Sidereal, Venus Heliacal Rise, & 7.02 .04 .05 .14 & February 8, 310 BC \\
Node & & \\
Copán Stela C , Pre-Era Deep Time base, 1 Ajaw 10.19.14.17.00 & February 11, 3907 BC \\
\hline
\end{tabular}

Opposite the August 13 zenith, February 8-9 is frequently referenced both in texts from Copán and at other sites north of $14.8^{\circ} \mathrm{N}$. This seasonal position was apparently used to time the accession events of several kings in Copán, Tortuguero, and Naranjo (Table 1a). In addition, we find that this date served as a significant seasonal anchor, with a Haab 365-day New Year (and the simultaneous conquest of Naranjo) commemorated on this day in Tikal Temple IV, Lintel 2 (Table 1b). In fact, another deep time calculation from Copán Stela C counts back to the pre-Era date February 11, 3907 BC, using the 584285 GMT (Table 1d). As on Naranjo Altar 1, it references a water serpent. It appears that the Copán astronomers may have also targeted the February 8-9 solar nadir, and the two-day error here provides additional evidence for the use of the Copán tropical year that Teeple identified in Stela A, which was commissioned by the ruler 18-Ubaah-K'awiil one $\mathrm{k}^{\prime}$ atun after he erected Stela C.

3) The Heliacal Rise of Venus: Returning to Naranjo Altar 1, on the date 7.2.4.5.14, February 8, 310 BC (2/13 Julian), Venus was heliacally rising as Morning Star (Fig. 9b), and it would have been first visible about four days earlier. The possible intentionality of this back-calculation takes on an added significance when we see that the Dresden Venus Table also utilizes this same February solar nadir in Copán as a base date. Similarly, the South panel of the West door of Copán Temple 11 uses this same February nadir (Table 1c), while this text also specifically references Venus as EK' in an unusual verb at B5, though Venus is not heliacally rising. What is extraordinary about the corresponding date on Temple 11 is that it occurs very close to a total eclipse of the moon at the zenith one day earlier (Fig. 10). This precisely suggests the utility of the solar nadir for the purposes of commensurating the tropical year, the eclipse cycles, and the sidereal position of the lunar zenith by recording the rare event of a lunar zenith eclipse. This is very similar to the technique apparently used in the Dresden Serpent Series. Furthermore, Aveni (1992) notes that the Dresden Venus Table commensurates the cycles of Venus with the moon, and we find repeating solar eclipses that are in precisely around the time of this February nadir.

4) The Lunar Node: Tedlock (1982: 189) notes that the K'iche' determine the time of the solar nadir when the full moon reaches the zenith. Returning again to the rare event 


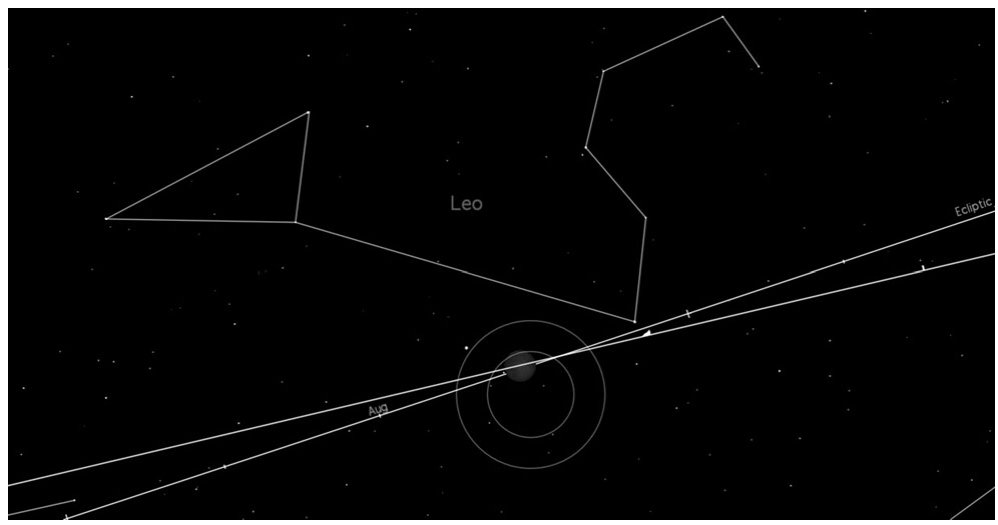

Figure 10. Copán Temple 11, South Panel West Door. Total lunar eclipse at zenith, one day before 9.17.0.0.16. On evening of solar nadir, February 8, 771 AD. Image by author courtesy of Starry Night Pro 6.2.3: Imaginova.

back-calculated on Naranjo Altar 1, we find that on this date of February 8, 310 BC, the sun was indeed precisely at a lunar node (Fig. 9b), indicating that an eclipse close to the Copán zenith would have been imminent, much like in the historical example from Copán Temple 11. On Naranjo Altar 1, the moon was 6 days prior to new. Given the known errors that Teeple (1930) first identified in Classic Maya calculations of the lunar synodic cycle, it is conceivable that the intention was to target a solar eclipse using the Palenque lunar cycle, which comes to within two days of a solar eclipse at the nadir. The text associated with this date on Naranjo Altar 1 indicates that CHAN-chi-pu-yuAJAW oversaw an event involving a locative suffix $n i b$ affixed to the eye of the Jaguar War God (T680), elsewhere depicted as one of the three patrons of Glyph C in the Lunar Series (Grube \& Schele 1993: 2). Linden (1996: 354) proposed that each of these patrons represents one of three canonical six-month lunar semesters useful for tracking eclipses over an 18-month period. Milbrath (1999: 124-125) further notes that iconography of the Jaguar War God clusters most frequently during the winter dry season, while he is also associated with Venus, the moon, and eclipses. Here, the reference seems to suggest that an eclipse event was intentionally calculated.

Unfortunately, the much larger deep time interval at the beginning of Naranjo Altar 1 is missing a coefficient for the 360-day periods, and the initial date appears to be in error (B2-A3). Not surprisingly, some of these vast calculations into the most ancient deep time periods produce errors. While it is possible to correct some, others remain undecipherable. In this case, an exploration of the larger deep time interval on Naranjo Altar 1 is a worthy endeavor for another discussion. Significantly, like several other vast deep time intervals, Naranjo Altar 1 also references the 3-11-PIK title (H12), involving an interval mentioned on Tikal MT 26. Boot (2005: 347) explains that it was Proskouriakoff (1970) followed by Gaida (1990) who first interpreted this as a vast interval of 33 Bak'tuns that counts forward into the future from the Era base. Looper (2002) more recently proposed that it can also be read as a shorter interval of $3 \times 8,660$ days $=25,980$ days. He suggests that kings would receive the 3-11-Pik Ajaw title only when they are old enough to have overlapped with greater than two of the 8660-day trimesters, much like a 4-K'atun-Ajaw title. Both MacLeod (2008; see Van Stone 2010: 13-17) and I (Grofe 2003) independently noticed that this smaller interval is coincidentally roughly equivalent to one day of precessional drift, while the larger interval is close to half of the 26,000-year cycle of precession. MacLeod proposes that the smaller interval reflects the larger, and 
kings thereby link their own lives to the vast intervals of deep time involving precession. Since we find 3-11-Pik mentioned as early as the Papagayo Step in Copán, it may qualify as the oldest reference to a deep time interval after the foundation of the Long Count itself.

\section{Conclusion}

The evidence within this paper strongly supports the proposal that deep time intervals contain precise calculations of the sidereal and tropical years. While partially validating the GMT, many of these results remain significant independent of any correlation, and further research is required to identify any similar patterns in other deep time intervals. The sidereal parallel found on Tortuguero Monument 6 , which references the completion of the thirteenth Bak'tun, must be seen within the context of numerous, similar deep time intervals that appear to link historical sidereal positions of the sun with like-in-kind mythological events. While the present study contends with the astronomical evidence, the political, astrological, and cosmological purpose of these measurements remains to be explored. With any luck, and further collaboration, interest in this project will continue far beyond the passing of the upcoming thirteenth Bak'tun. If nothing else, it is my hope that the arrival of this auspicious date will give us pause to celebrate and learn from the millennia of intellectual and cultural achievements developed by the people of Mesoamerica.

\section{References}

Apenes, O. 1936, Possible derivation of the 260 day period of the Maya calendar. Ethnos 1, 5-8.

Aveni, A. F. 1992, The Moon and the Venus Table: an example of commensuration in the Maya calendar. In A. F. Aveni (ed.), The Sky in Mayan Literature, Oxford University Press, New York, pp. $87-101$.

Aveni, A. F. 2001, Skywatchers, University of Texas Press, Austin.

Aveni, A. F. 2009, The End of Time: the Maya Mystery of 2012, University Press of Colorado, Boulder.

Aveni, A. F., Bricker, H. M., \& Bricker, V. R. 2003, Seeking the sidereal: observable planetary stations and the ancient Maya record. Journal for the History of Astronomy 34, 145-161.

Aveni, A. F., Dowd, A. S., \& Vining, B. 2003, Maya calendar reform? Evidence from orientations of specialized architectural assemblages. Latin American Antiquity 14(2), 159-178.

Aveni, A. F. \& Hartung, H. 1981, The observation of the Sun at the time of passage through the zenith in Mesoamerica. Archaeoastronomy no. 3 (supplement to Journal for the History of Astronomy 12), S51-S70.

Aveni, A. F. \& Hartung, H. 1989, Uaxactún, Guatemala, Group E and similar assemblages: an archaeoastronomical reconsideration. In A.F. Aveni (ed.), World Archaeoastronomy, Cambridge University Press, Cambridge, pp. 441-461.

Beyer, H. 1943, The Long Count position of the Serpent Number dates. Proceedings of the 27th ICA, Mexico, 1939, Mexico City, pp. 401-405.

Boot, E. 2005, Continuity and Change in Text and Image at Chichén Itzá, Yucatán, Mexico: a Study of the Inscriptions, Iconography, and Architecture at a Late Classic to Early Postclassic Maya Site, CNWS Publications vol. 135, CNWS, Leiden.

Bricker, V. R. \& Bricker, H. M. 1988, The seasonal table in the Dresden Codex and related almanacs. Archaeoastronomy no. 12 (supplement to Journal for the History of Astronomy 19), S1-S62.

Bricker, V. R. \& Bricker, H. M. 1992, Zodiacal references in the Maya codices. In A.F. Aveni (ed.), The Sky in Mayan Literature, Oxford University Press, New York, pp. 148-183.

Broda, J. 2000, Mesoamerican astronomy and the ritual calendar. In H. Selin (ed.), Astronomy Across Cultures, Kluwer, Dordrecht/Boston/London, pp. 225-267. 
Broda, J. 2006, Zenith observations and the conceptualization of geographical latitude in ancient Mesoamerica: a historical interdisciplinary approach. In T.W. Bostwick \& B. Bates (eds), Viewing the Sky through Past and Present Cultures: Selected Papers from the Oxford VII International Conference on Archaeoastronomy, Pueblo Grande Museum Anthropological Papers no. 15, Phoenix, pp. 183-212.

Capitaine, N., Wallace, P. T., \& Chapront, J. 2003, Expressions for IAU 2000 precession quantities. Astronomy \& Astrophysics 412, 567-586.

Coe, M. D. 1994, Mexico: from the Olmecs to the Aztecs, Thames and Hudson, New York.

Coggins, C. 1982, The zenith, the mountain, the center, and the sea. In A.F. Aveni \& G. Urton (eds), Ethnoastronomy and Archaeoastronomy in the American Tropics, Dumbarton Oaks, Washington DC, pp. 49-68.

Edmonson, M. 1988, The Book of the Year: Middle American Calendrical Systems, University of Utah Press, Salt Lake City.

Evans, J. 1998, The History and Practice of Ancient Astronomy, Oxford University Press, New York.

Gaida, M. 1990, Die kulturelle und politisch-ökonomische Stellung Copans im Maya-Gebiet in der klassischen Zeit (300-900 n. Chr.), Beiträge zur allgemeinen und Vergleichenden Archäologie, Bonn.

Girard, R. 1948, El Calendario Maya-Mexica: Origen, Función, Desarrollo y Lugar de Procedencia, Editorial Stylo, Mexico City.

Girard, R. 1966, Los Mayas: Su Civilización, su Historia, sus Vinculaciones Continentales, Libro Mex, Mexico City.

Grofe, M. J. 2003, Calculations of the Tropical Year and precessional cycles: two bone fragments from Tikal Burial 116. Unpublished paper presented for Mesoamerican Writing Systems, NAS 191 for Dr. Martha J. Macri, University of California-Davis, June 5, 2003. Available from the author.

Grofe, M. J. 2007, The Serpent Series: Precession in the Maya Dresden Codex. Dissertation for the University of California at Davis.

Grofe, M. J. 2010, The Copán Baseline: $K^{\prime}$ atun 9.11.0.0.0 and the Three Hearthstones in Orion. Presentation at the 75th SAA Meeting, St. Louis.

Grube, N. \& Schele, L. 1993, Naranjo Altar 1 and Rituals of Death and Burials, Texas Note No. 54, CHAAAC, Austin.

Jenkins, J. M. 1998, Maya Cosmogenesis 2012: the True Meaning of the Maya Calendar EndDate, Bear \& Co, Santa Fe NM.

Jones, C. \& Satterthwaite, L. 1982, The Monuments and Inscriptions of Tikal: the Carved Monuments. Tikal Report No. 33, Part A, University Museum Monograph 44, University of Pennsylvania, Philadelphia.

Linden, J. 1996, The Deity Head variants of Glyph C. In M. J. Macri \& J. McHargue (eds), Eighth Palenque Round Table, 1993, Vol. x, Pre-Columbian Art Research Center, San Francisco, pp. 369-377.

Looper, M. G. 2002, The 3-11-pih Title in Classic Maya Inscriptions, Glyphdwellers Report 15, Maya Hieroglyphic Database Project, Davis.

Looper, M. G. 2003, Lightning Warrior: Maya Art and Kingship at Quirigua, University of Texas Press, Austin.

MacLeod, B. 2008, The 3-11-Pik Formula, Lecture delivered at UT Austin Maya Meetings, University of Texas, March 2, 2008.

Malmström, V. 1973, Origin of the Mesoamerican 260-day calendar. Science 181, 939-941.

Malmström, V. 1978, A reconstruction of the chronology of Mesoamerican calendrical systems. Journal for the History of Astronomy 9, 105-116.

Malmström, V. 1997, Cycles of the Sun, Mysteries of the Moon: the Calendar in Mesoamerican Civilization, University of Texas Press, Austin.

Martin, S. \& Grube, N. 2000, Chronicle of the Maya Kings and Queens: Deciphering the Dynasties of the Ancient Maya, Thames \& Hudson, London.

Meeus, J. \& Savoie, D. 1992, The history of the Tropical Year. Journal of the British Astronomical Association 102(1), 40-42.

Mendez, A., Barnhart, E. L., Powell, C., \& Karasik, C. 2005, Astronomical observations from the Temple of the Sun. Archaeoastronomy: The Journal of Astronomy in Culture 19, 44-73. 
Merrill, R. H. 1945, Maya sun calendar dictum disproved. American Antiquity 10, 307-311.

Milbrath, S. 1988, Astronomical images and orientations in the architecture of Chichen Itza. In A.F. Aveni (ed.), New Directions in American Archaeoastronomy, BAR International Series 454, British Archaeological Reports, Oxford, pp. 57-79.

Milbrath, S. 1999, Star Gods of the Maya: Astronomy in Art, Folklore, and Calendars, University of Texas Press, Austin.

Moyer, G. 1981, The origin of the Julian Day system. Sky $\&$ Telescope 61, 311-313.

Neugebauer, O. 1969, The Exact Sciences in Antiquity, Dover, Mineola.

North, J. 2008, Cosmos: an Illustrated History of Astronomy and Cosmology, University of Chicago Press, Chicago.

Nuttall, Z. 1928, Nouvelles lumières sur les civilizations americaines et le système du calendrier. Proceedings of the 22nd ICA, Rome, pp. 119-148.

Proskouriakoff, T. 1970, On two inscriptions at Chichen Itza. Papers of the Peabody Museum $61,457-467$.

Rice, P. M. 2007, Maya Calendar Origins: Monuments, Mythistory, and the Materialization of Time, University of Texas Press, Austin.

Severin, G. 1981, The Paris Codex: Decoding an Astronomical Ephemeris, American Philosophical Society, Philadelphia.

Šprajc, I. 2001, Orientaciones Astronómicas en la Arquitectura Prehispánica del Centro de México, Instituto Nacional de Antropología e Historia, Mexico City.

Tedlock, B. 1982, Time and the Highland Maya, University of New Mexico Press, Albuquerque.

Teeple, J. 1930, Maya astronomy. Contributions to American Archaeology 1(2) (Carnegie Institution of Washington Publication 403), 29-116.

Thompson, J. E. S. 1927, A correlation of the Mayan and European calendars. Field Museum of Nat. Hist. Publ. 241 (Anth. Series 27(1)), 3-22.

Thompson, J. E. S. 1932, The Solar Year of the Mayas at Quirigua, Guatemala. Field Museum of Nat. Hist. Publ. 315 (Anth. Series 17(4)), 366-421.

Thompson, J. E. S. 1950, Maya Hieroglyphic Writing: an Introduction, CIW Publication 589, Carnegie Institution of Washington, Washington DC.

Tichy, F. 1981, Order and relationship of space and time in Mesoamerica: myth or reality? In E.P. Benson (ed.), Mesoamerican Sites and World-Views, Dumbarton Oaks, Washington DC, pp. 217-245.

Toomer, G. J. 1978, Hipparchus. In C.C. Gillispie (ed.), Dictionary of Scientific Biography, Vol. 15, Charles Scribner's Sons, New York, pp. 207-224.

Van Stone, M. 2010, 2012: Science and Prophecy of the Ancient Maya, Tlacaélel Press, Imperial Beach. 